\title{
Infección fatal por Trichosporon asahii en una recién nacida de pretérmino
}

\author{
Carlos J. Téllez-Castillo, María Gil-Fortuño, Irene Centelles-Sales, \\ Susana Sabater-Vidal y Francisco Pardo Serrano
}

\section{Trichosporon asahii fatal infection in a preterm newborn}

We present a case of Trichosporon asahii fatal infection recognized post mortem in a premature newborn baby of 685 g. Trichosporon asahii isolated from endovascular catheters and endotraqueal tube, is an opportunistic yeast described like an emergent pathogen in serious systemic infections and nosocomial infections in the neonatal intensive care units. The colonization and disease by this uncommon microorganism, usually is unspecific and has similar clinical presentation to other fungal infections with a bad prognosis.

Key words: Trichosporon asahii, fungal infection, preterm newborn.

Palabras clave: Trichosporon asahii, infección fúngica, prematurez.

\section{Introducción}

T

richosporon asahii es una levadura oportunista descrita como un patógeno emergente en infecciones diseminadas e infecciones nosocomiales en las unidades de cuidados intensivos neonatales $^{1-3}$. La presentación clínica por este microorganismo poco común, suele ser inespecífica y de mal pronóstico, similar a otras micosis. Actualmente, la mayoría de casos descritos en la literatura científica ha relacionado la enfermedad invasora por $T$. asahii con recién nacidos pretérmino de muy bajo peso al nacimiento, así como con la antibioterapia de amplio espectro, nutrición parenteral y cateterización prolonga$\mathrm{da}^{1,2}$; por lo que se destaca la importancia de sospechar este micoorganismo ante una infección neonatal grave.

Presentamos un caso clínico de infección sistémica grave causados por $T$. asahii en una recién nacida de pretérmino hospitalizada en unidad de cuidados intensivos neonatales en Castellón, España.

\section{Caso Clínico}

Se presenta el caso de una recién nacida de pretérmino, con 24 semanas de edad gestacional y peso de nacimiento de 685 g. Embarazo gemelar controlado, por fecundación in vitro. Tras un parto vaginal de presentación cefálica y sufrimiento fetal (Apgar 4-6), debió ser intubada en la sala de parto. Se trasladó a la unidad de cuidados intensivos siendo conectada a ventilación mecánica. Permaneció desde el primer día con nutrición parenteral y catéter venoso central y precisando administración de surfactante pulmonar exógeno con escasa respuesta. Se obtuvieron muestras para hemocultivo y urocultivo al ingreso e inició tratamiento empírico de sepsis neonatal precoz (ampicilina y gentamicina). Tras cinco días de tratamiento antimicrobiano presentó empeoramiento clínico y alteración de exámenes laboratorio por lo que se cambió la antibioterapia para cobertura de sepsis nosocomial (vancomicina y ceftazidima) y se obtuvieron nuevas muestras para cultivo (sangre, orina y LCR).

A la semana de vida se retiró el catéter de la arteria umbilical, en el que se aisló Staphylococcus epidermidis sensible a vancomicina. Se suspendió la ceftazidima y se mantuvo la vancomicina durante 10 días más. Los cultivos realizados (sangre, orina y LCR) fueron negativos. Persistieron las alteraciones hemodinámicas, respiratorias y hematológicas, con un empeoramiento progresivo hasta el fallecimiento a los 20 días de vida. Tras su deceso se cultivaron los catéteres (venoso central y arterial) y el tubo endotraqueal en caldo de enriquecimiento tioglicolato y en agar chocolate. En todos ellos, a las 24 horas de incubación a 37 ${ }^{\circ} \mathrm{C}$ se observó, en cultivo puro, colonias secas de coloración crema y superficie rugosa que fueron resembradas en agar Albicans (Biomerieux ${ }^{\circledR}$ ) y en agar SGC2 (Biomerieux ${ }^{\circledR}$ ) e incubadas a $30^{\circ} \mathrm{C}$. Posteriormente, se realizó su identificación mediante tarjeta ID Yeast en el sistema automatizado Vitek (Biomerieux ${ }^{\circledR}$ ), obteniéndose como resultado T. asahii. Paralelamente, se realizó visión directa al microscopio en la que se
Castellón de la Plana, España Hospital General de Castellón Laboratorio de Microbiología y Parasitología (CTT-C, MG-F, SS-V, FPS).

UCI pediátrica (IC-S)

Recibido: 25 agosto 2007 Aceptado: 31 enero 2008

Correspondencia a: Carlos José Téllez Castillo cartecas@gmail.com 
observaron hifas ramificadas con artroconidios intercalares y terminales de forma rectangular. Por último, se comprobó la positividad de la ureasa como diagnóstico diferencial con Geotrichum sp. Para el estudio de la susceptibilidad se practicó un Sensititre YeastOne Y07 (Trek Diagnostic Systems®) que, en su lectura a las 24 horas, arrojó una CIM de $16 \mu \mathrm{g} / \mathrm{ml}$ para fluconazol, $0,25 \mu \mathrm{g} / \mathrm{ml}$ para itraconazol y $1 \mu \mathrm{g} / \mathrm{ml}$ para ketoconazol, para 5-fluocitosina una CIM de $0,5 \mu \mathrm{g} / \mathrm{ml}$ y para anfotericina B una CIM, a las 48 horas, de $2 \mu \mathrm{g} / \mathrm{ml}$. En los cultivos del otro gemelo, que también ingresó en la Unidad de Ciudados Intensivos Neonatales, no se aisló patógeno de interés alguno, teniendo una buena evolución clínica en su estadía hospitalaria.

\section{Discusión}

Trichosporon asahii, anteriormente clasificado como Trichosporon beigelii, es un microorganismo poco común entre los patógenos causantes de infecciones nosocomiales en las unidades de cuidados intensivos neonatales. Ha sido descrito como un patógeno emergente en fungemias ${ }^{1-4}$. Silva et al, describieron el primer caso de T. asahii como agente de infección urinaria nosocomial en Chile en pacientes con catéter vesical e internados en la Unidad de Cuidados Intensivos $^{5}$. En adultos inmunocomprometidos sometidos a quimioterapia, tratamiento inmunosupresor o trasplante de órganos sólidos y precursores hematopoyéticos, se ha descrito como agente causal de infecciones respiratorias, endocarditis en válvula protésica, peritonitis, infecciones urinarias, infección cutánea grave y fungemia ${ }^{6-8}$.

La colonización y enfermedad invasora por T. asahii en neonatos es poco frecuente, y la mayoría de casos descritos corresponde a recién nacidos de pretérmino con muy bajo peso al nacimiento, relacionándose también con condiciones como antibioterapia de amplio espectro, nutrición parenteral y cateterización prolongada $^{1,2,4,9}$. La infección diseminada en estos recién na- cidos suele ocasionar manifestaciones inespecíficas, de presentación clínica similar a otras infecciones fúngicas neonatales y asociándose a una elevada mortalidad $^{1,4}$; el presente caso es un claro ejemplo: una neonata de pretérmino, con bajo peso, que fue expuesta a antibioterapia de amplio espectro, nutrición parenteral y cateterización prolongada. No existe una expresión clínica específica para diferenciarla de otra infección fúngica diseminada, en concordancia con la mayoría de casos reportados en la literatura científica ${ }^{1-4,9-11}$.

Identificación del microorganismo. Estudios realizados han comprobado que el sistema Vitek (Biomerieux $\left.{ }^{\circledR}\right)$ identifica de manera correcta a 93\% de las levaduras comunes; sin embargo, sólo 55\% de las no comunes fueron identificadas de modo correcto, entre estas últimas Trichosporon $\mathrm{sp}^{12}$. Los métodos de identificación rápida son recomendables por su rápida y fácil ejecución e interpretación y ser relativamente económicos, estando al alcance de la mayoría de los laboratorios. Así mismo, proporcionan una identificación rápida de levaduras y microorganismos levaduriformes $^{5,7,11,12}$. No obstante, en la actualidad, estudios realizados por Rodríguez-Tudela JL y cols ${ }^{13}$, han demostrado que los métodos moleculares (RPC y secuenciación de $\mathrm{ADN}$ ) poseen una mayor sensibilidad y especificidad para la identificación correcta de las diferentes especies de este microorganismo levaduriforme, siendo necesarias tecnología y entrenamiento adecuados para llevar a cabo dichas técnicas ${ }^{6,7,13}$. Debido a que nuestro laboratorio pertenece a un hospital asistencial, de tamaño medio -545 camas, correspondiente al área 02 de la Comunidad Valenciana y atiende a 285.309 habitantes- que exige una respuesta rápida por parte de los médicos clínicos, y ya que nuestro sistema automatizado reportó un resultado satisfactorio y preciso ante las pruebas bioquímicas, concordantes entre todos los cultivos y con el aspecto macro y microscópico de la colonia, no consideramos necesario remitirla para confirmación por métodos moleculares a un laboratorio externo*.

\section{*Nota de la Editora de Sección}

Estudios recientes sostienen que el sistema de identificación Vitek ID yeast identifica en forma correcta sobre $98 \%$ de las levaduras aisladas desde muestras clínicas. Dentro de este porcentaje, hay un 19\% en que la identificación, aunque correcta, se obtiene con un menor nivel de discriminación. Trichosporon se encuentra dentro de esta última categoría ya que se aísla con una frecuencia mucho menor que las levaduras comunes. En estos casos, se recomienda completar el estudio con métodos adicionales (morfológicos, bioquímicos y moleculares), por lo que la cepa siempre debe ser enviada a un laboratorio de referencia.

\section{Referencias}

1. Hata D J, Hall L, Fothergill A W, Larone D H, Wengenack N L. 1 Multicenter evaluation of the new VITEK 2 advanced colorimetric yeast identification card. J Clin Microbiol 2007; 45: 1087-92.

2. Sanguinetti M, Porta R, Sali M, La Sorda M, Pecorini G, Fadda G, et al. Evaluation of VITEK 2 and rapid yeast plus systems for yeast species identification: Experience at a large clinical microbiology laboratory. J Clin Microbiol 2007; 45: 1343-6. 
En el presente caso, se obtuvieron elevadas CIM in vitro frente a los azoles y anfotericina $\mathrm{B}$, lo que concuerda con los estudios que demuestran la escasa sensibilidad de $T$. asahii a estos antifúngicos ${ }^{1,4,7,13}$. Se han encontrado cepas resistentes y sensibles a 5flucitosina ${ }^{7}$; en nuestro caso la cepa presentó una CIM de 0,5 $\mu \mathrm{g} / \mathrm{ml}$ por lo que se consideró sensible.

La escasa susceptibilidad a anfotericina B in vitro contrasta con la buena evolución clínica de los pacientes a los que se ha administrado este antifúngico en los casos publicados ${ }^{1,9}$.

\section{Conclusión}

Se desprende de la experiencia relatada que, ante un neonato con los factores de riesgo enunciados, sin respuesta al tratamiento antimicrobiano de amplio espectro y con mala evolución clínica, debe sospecharse una infección fúngica invasora. Por ello recomenda- mos obtener, tan pronto como sea posible, muestras representativas para cultivos que permitan detectar, mediante las características morfológicas, microscópicas y bioquímicas descritas, este tipo de microorganismo; así mismo realizar estudios de susceptibilidad para el correcto manejo terapéutico de dicho patógeno.

\section{Resumen}

Se presenta un caso fatal de infección por Trichosporon asahii diagnosticado post mortem en una neonato de pretérmino que pesó 685 grs al nacer. De los cultivos de catéteres y del tubo endotraqueal se aisló T. asahii, levadura oportunista descrita como un patógeno emergente en infecciones sistémicas graves e infecciones nosocomiales en las unidades de cuidados intensivos neonatales. La colonización y enfermedad por este microorganismo poco común suele ser inespecífica y con mal pronóstico, de presentación clínica similar a otras infecciones fúngicas.

\section{Referencias}

1.-. Panagopoulou P, Evdoridou J, Bibashi E, Filioti J, Sofianou D, Kremenopoulus G, et al. Trichosporon asahii: an unusual cause of invasive infection in neonates. Pediatr Infect Dis J 2002; 21: 169-70.

2.- Da Silva Rodríguez G, Ubatuba de Faria R, Silva Guazzalli L, De Matos Oliveira F, Severo L C. Infección nosocomial por Trichosporon asahii: revisión clínica de 22 casos. Rev Iberoam Micol 2006; 23: 85-9.

3.- Martín Parra M B, Alberola M J, Lázaro A, Martín Arenos J M. Septicemia neonatal por Trichosporon asahii: un patógeno poco habitual. Bol Soc Val Pediatr 2005; 25: 167.

4.- Herrera M L, Moya T, Duarte I, Bogantes A. Fungemia por Trichosporon beigelii: reporte del primer caso en Costa Rica. Rev Méd Hosp Nac Niños 1995; 30: 27-30.

5.- Silva V, Zepeda G, Alvareda D. Infección urinaria nosocomial por Trichosporon asahii. Primeros dos casos en Chile. Rev Iberoam Micol 2003; 20: 21-3.

6.- Ahmad S, Al-Mahmeed M, Khan Z U. Characterization of Trichosporon species isolated from clinical specimens in Kuwait. J Med Microbiol 2005; 54: 639-46

7.- Chowdhary A, Ahmad S, Khan Z U, Doval D C, Randhawa H S. Trichosporon asahii as an emerging agent of disseminated trichosporonosis: a case report and update. Indian J Med Microbiol 2004; 22: 16-22.

8. - Nakagawa T, Nakashima K, Takaiwa T, Negayama K. Trichosporon cutaneum (Trichosporon asahii) infection mimicking hand eczema in patient with leukemia. J Am Acad Dermatol 2000; 45: 929-31.

9.- Yildiran A, Kücüködük S, Saniç A, Belet N, Güvenli A. Disseminated Trichosporon asahii infection in a preterm. Am J Perinatol 2003; 20: 260-71.
10.- Rivera P, Hernández F, Santamaría S, Salas I, García J. Diagnóstico diferencial de infecciones sistémicas por Trichosporon beigelii. Rev Costarric Cienc Méd 2003; 24: 63-70.

11.- Krcmery V, Laho L, Huttova M, Ondrusova A, Kranlinsky K, Pevalova L, et al. Aetiology, antifungal susceptibility, risk factors and outcome in 201 fungaemic children: data from a 12-year prospective national study from Slovakia. J Med Microbiol 2002; 51: 110-16.

12.- Dooley D P, Beckius M L, Jeffrey B S. Misidentification of clinical yeast isolates by using updated Vitek Yeast Biochemical Card. J Clin Microbiol 1994; 32: 2889-92.

13.- Rodríguez-Tudela J L, Díaz-Guerra T L, Mellado E, Cano V, Tapia C, Perkins A, et al. Susceptibility patterns and molecular identification of Trichosporon species. Antimicrob Agents Chemother 2005; 49: 4026-34. 